$\begin{array}{ll} & \text { Etnográfica } \\ \text { etnográfica } & \text { Revista do Centro em Rede de Investigação em }\end{array}$

Antropologia

vol. 11 (1) | 2007

Vol. 11 (1)

\title{
Usos da ruralidade na arquitectura paisagista
}

The uses of rurality in landscape architecture

\section{Sandra Xavier}

\section{(2) OpenEdition \\ Journals}

\section{Edição electrónica}

URL: https://journals.openedition.org/etnografica/1908

DOI: 10.4000/etnografica. 1908

ISSN: 2182-2891

\section{Editora}

Centro em Rede de Investigação em Antropologia

\section{Edição impressa}

Data de publição: 1 maio 2007

Paginação: 165-188

ISBN: 0873-6561; E-ISBN 2182-2891

ISSN: 0873-6561

\section{Refêrencia eletrónica}

Sandra Xavier, «Usos da ruralidade na arquitectura paisagista», Etnográfica [Online], vol. 11 (1) | 2007, posto online no dia 25 setembro 2012, consultado o 12 fevereiro 2022. URL: http://

journals.openedition.org/etnografica/1908; DOI: https://doi.org/10.4000/etnografica. 1908

\section{(c) (7) (8)}

Etnográfica is licensed under a Creative Commons Attribution-NonCommercial 4.0 International License. 


\title{
Usos da ruralidade
}

\section{na arquitectura paisagista}

\section{Sandra Xavier}

\begin{abstract}
Procurarei pensar os projectos e o processo de trabalho do arquitecto paisagista João Gomes da Silva através do conceito de objectificação da cultura de Richard Handler. João Gomes da Silva segue a escola de arquitectura paisagista fundada por Francisco Caldeira Cabral e inclui frequentemente tipologias rurais, como elementos representativos da identidade do lugar, em jardins públicos e privados, em espaços públicos e urbanos. Influenciado pelo arquitecto Álvaro Siza Vieira e, através dele, pelo Inquérito à Arquitectura Popular em Portugal, também dedica particular atenção aos modos populares de construção da paisagem. Estes surgem nos seus projectos como modos de construção que marcam a cultura e a identidade de um território sendo, como tal, esteticamente valorizados.

PALAVRAS-CHAVE: arquitectura paisagista, genius loci, tipologias rurais, construções populares, obectificação, esteticização.
\end{abstract}

O TERRITÓRIO QUE HOJE HABITAMOS E NO QUAL DESENVOLVEMOS AS nossas actividades quotidianas é cada vez menos construído, configurado e ordenado única e exclusivamente por nós. O seu desenho, organização e construção estão a ser progressivamente transferidos para as mãos de especialistas. Arquitectos, arquitectos paisagistas, agrónomos, biólogos, urbanistas, engenheiros e até artistas plásticos integram o conjunto daqueles a quem legalmente é conferida a tarefa de estruturar, sempre em confronto e diálogo com o poder político e económico, os espaços onde vivemos. Com a progressiva valorização da paisagem decorrente das críticas ao modernismo, da consciencialização ambiental e do desenvolvimento do turismo, das indústrias do lazer e da imagem, os arquitectos paisagistas têm vindo a adquirir nos últimos anos um papel importante entre o conjunto dos especialistas responsáveis pelo desenho do território. Procurar compreender as práticas e representações dos arquitectos paisagistas é por isso interrogar um universo de sentido que crescentemente interfere no nosso imaginário social e nas nossas práticas espaciais quotidianas. 
Com esse objectivo e seguindo uma metodologia próxima da que Bruno Latour e Steve Woolgar (1986 [1979]) utilizam para os estudos de ciência, desenvolvi entre Setembro de 2002 e Junho de 2003 trabalho de campo num dos ateliês de arquitectura paisagista que mais se tem destacado em Portugal, através de projectos como os jardins Garcia de Orta, os espaços exteriores do recinto da Expo'98 ou a paisagem do Museu de Arte Contemporânea em Serralves.

A Global era dirigida pelo arquitecto paisagista João Gomes da Silva e pela sua mulher, a arquitecta paisagista Inês Norton de Matos, ambos licenciados em Évora. João Gomes da Silva concluiu a licenciatura em 1985. Foi ainda neste período de formação que se distanciou, como frequentemente realça, da "perspectiva funcionalista, moderna e americana" perfilhada pelos seus professores de projecto, alegadamente veiculadores de uma "linguagem alheia à nossa cultura”. Este afastamento traduz-se também em termos metodológicos: rejeita a abordagem modernista, baseada no mito da originalidade e da criatividade da análise que parte do zero, liberta de citações e referências à história ou outros projectos; e procura integrar no seu trabalho os contributos da história da arquitectura e da arquitectura paisagista bem como elementos históricos e vernaculares da paisagem preexistente. Neste contexto, aproximou-se também de Gonçalo Ribeiro Telles, em quem aprecia sobretudo a atenção que confere à cultura e à história de cada lugar.

A noção de genius loci, tal como ela é formulada em 1979 pelo arquitecto norueguês Cristian Norberg-Schulz (1981 [1979]), virá, deste modo, a marcar os projectos e o processo de trabalho de João Gomes da Silva, tornando-se essencial para a compreensão das suas propostas. Tal como para Norberg-Schulz, também para Gomes da Silva qualquer construção deve procurar revelar ou explicitar a identidade, o carácter próprio ou, se quisermos, o génio do lugar onde se insere. Para Norberg-Schulz, é a arquitectura que revela o significado escondido do meio no qual se integra. Sem ela, este permaneceria invisível, inacessível. Com ela, o sentido do sítio torna-se visível e, por isso, constrói o lugar. Lugar carregado de sentido. Lugar humanamente vivido. Lugar simbólico e existencial. Lugar habitado. Revelar o sentido do sítio é revelar o seu carácter próprio ou a sua identidade. É a arquitectura, "ponto" ou "implantação" que marca e torna visível a identidade de cada lugar. Como? "Visualizar, completar, simbolizar, reunir são (...) os processos gerais de implantação (...). Heidegger ilustra este problema com a imagem do ponto; um edifício que visualiza, simboliza, reúne e transforma o meio num conjunto unificado" (Norberg-Schulz 1981 [1979]:18 - tradução minha).

Procurarei neste artigo pensar criticamente estes processos através do conceito de objectificação da cultura de Richard Handler (1988). Objectificar a cultura é transformar determinados aspectos da vida social em

objectos discretos para serem estudados, catalogados e exibidos. Isto envolve selecção e reinterpretação. $\mathrm{O}$ objectificador olha para um meio 
familiar e descobre que é composto por traços tradicionais, coisas que ele extrai daquilo que até aí era tido como um fundo cultural dado por adquirido e transforma em especímenes típicos. Mas seleccionar aspectos do mundo social como traços, e a seguir isolar os traços escolhidos num novo contexto - fotografá-los, inscrevê-los, representá-los num palco, expô-los num museu - necessariamente muda o significado que esses traços têm para os objectificadores, colectores de traços ou espectadores. (...) Novos critérios de classificação da experiência social entram em jogo que discriminam como entidades significativas o que antes eram práticas não marcadas, ou que atribuem novos significados (por exemplo, "tradicional”) a práticas anteriormente marcadas e objectificadas de outra forma (Handler 1988: 77 - tradução minha).

Procurarei aqui demonstrar como a metodologia que João Gomes da Silva utiliza para explicitar a suposta identidade de um lugar assenta neste processo de selecção e transformação de preexistências em elementos representativos. Os elementos seleccionados são retirados do seu contexto e apresentados isoladamente, num projecto de arquitectura paisagista, como traços típicos e distintivos de um determinado lugar. Neste processo, o seu significado político, social, económico e estético altera-se. Perdem o sentido que tinham no contexto do qual foram retirados. Num outro contexto, os elementos seleccionados adquirem um novo sentido: aquele que o projecto de arquitectura paisagista lhes imprime. Eles são agora reificados como típicos e representativos de uma entidade geográfica e cultural específica e delimitada. Eles participam agora dos processos sociais e políticos constitutivos das identidades e diferenças. Eles participam na construção da identidade dos lugares.

Os projectos de Gomes da Silva seleccionam elementos da paisagem preexistente com a intenção de a explicitar. Mas, paradoxalmente, este processo altera o seu sentido. Os elementos são seleccionados e apropriados pela linguagem particular do projectista e revelam agora a leitura/compreensão do sítio de Gomes da Silva. Revelam as suas próprias concepções sociais, estéticas e disciplinares. Revelam o seu olhar sobre o sítio e sobre a cultura que diz manifestar-se na tipologia das implantações. Revelam o seu olhar sobre o sítio e sobre aqueles que o habitam. Procurar destacar, explicitar, revelar um determinado lugar é por isso nele intervir. É transformá-lo. Gomes da Silva sabe disso. E afirma-o. Conversámos sobre o papel da estética num projecto de arquitectura paisagista. Gomes da Silva não reduz a arquitectura paisagista à elaboração de uma imagem visualmente apelativa. Destaca as suas componentes funcionais, ecológicas e culturais. Mas a dimensão estética de um projecto é para ele também importante. É ela que distingue o trabalho do arquitecto paisagista por relação ao trabalho de geógrafos, agrónomos, engenheiros e 
outros profissionais que intervêm na organização e construção da paisagem. Segundo Gomes da Silva, o arquitecto paisagista deve chamar a atenção para a beleza da paisagem na qual intervém. Deve destacar ou realçar a beleza do lugar através de uma intervenção discreta e minimal, como poderá ser a construção de um percurso. Mas esta intervenção, por mais pequena e discreta que seja, altera o sentido do lugar preexistente. Apresenta-o e representa-o como belo. Gomes da Silva recorre a Duchamp para descrever e interpretar a sua própria metodologia. Faz apelo à noção de ready-made: objectos do quotidiano que, ao mudarem de contexto, sendo expostos numa galeria ou museu, se constituem como arte. Está assim a afirmar que o sentido dos objectos depende do contexto no qual são inseridos. Está a dizer que são os seus projectos que configuram como estética e artisticamente significativos determinados elementos da paisagem preexistente.

João Gomes da Silva inclui frequentemente nos seus projectos de espaços urbanos e jardins privados preexistências rurais e populares para ele reveladoras da identidade do sítio. Tipologias rurais e construções populares mudam assim de contexto e significado. São apropriadas e transformadas por uma cultura urbana. São apropriadas e transformadas por um olhar erudito. São configuradas como entidades histórica e culturalmente significativas. Adquirem valor estético e artístico. Passam a estar associadas ao lazer mesmo quando mantêm a sua função produtiva. Na primeira parte deste artigo, procurarei mostrar como neste aspecto João Gomes da Silva se revela herdeiro da escola de Gonçalo Ribeiro Telles e Francisco Caldeira Cabral e é influenciado por Álvaro Siza Vieira e, através dele, pelo Inquérito à Arquitectura Popular em Portugal realizado nos anos 50. Na segunda parte, irei falar do seu projecto para uma unidade de ecoturismo a criar na Herdade de Freixo, em Montemor-o-Novo, e procurarei demonstrar como através dele João Gomes da Silva selecciona, descontextualiza, reinterpreta e transforma, i.e., objectifica alguns elementos rurais e populares preexistentes no sítio.

\section{GONÇALO RIBEIRO TELLES: CAMPO E CIDADE}

Gonçalo Ribeiro Telles é um arquitecto paisagista que tem persistentemente chamado a atenção para a necessidade de se inserirem no interior da cidade espaços rurais e agrícolas. É nos conceitos de cidade, região e paisagem global que assentam os seus discursos, dentro e fora das universidades. Por exemplo, em 1995, numa conferência organizada pela Câmara Municipal de Matosinhos, Ribeiro Telles afirmava:

Um novo conceito de cidade deve ser pensado. (...) Em termos ecológicos, devemos partir do princípio de que a cidade e o campo são fases diferentes de um mesmo sistema: uma não pode viver sem a outra. 
A cidade pontual deu origem à cidade região. (...) Nela já não há fronteiras definidas entre os espaços urbano e rural.

(...) O homem do futuro, do século XXI (que está próximo...) não será rural nem urbano: será as duas coisas ao mesmo tempo sem as confundir.

$\mathrm{Na}$ cidade do futuro deve ser reintegrada a ruralidade e a agricultura, a tempo parcial e complementar, ou mesmo de determinadas especialidades.

Uma cidade/região, onde a ruralidade e a urbanidade estejam interligadas é fundamental para encarar o futuro (Telles 1996: 14-19).

Porque será que Ribeiro Telles defende com tanta convicção que é necessário incluir os espaços rurais no interior da cidade? De onde vem este seu fascínio pela ruralidade e, sobretudo, pela sua articulação com o urbano? Fernando Santos Pessoa explica este seu fascínio através da sua biografia.

Passou a juventude entre Coruche e Lisboa, e cedo se apaixonou quer pelas questões do mundo rural, onde se encontra a base da portugalidade, quer pelas questões urbanas e em especial da "sua" Lisboa, realidades que sempre defendeu, como o faz ainda hoje, como sendo espaços interligados da mesma realidade espacial e colectiva (Pessoa 2002: 19).

Mas as razões desta afeição são bastante mais complexas e multifactoriais, extravasando em grande parte as questões biográficas. Ribeiro Telles afirma que é importante integrar os elementos rurais no planeamento da cidade e, em particular, no planeamento da cidade de Lisboa porque eles fazem parte da história da cidade. A valorização da ruralidade encontra por isso o seu fundamento na manutenção do espírito do lugar. Como refere Santos Pessoa, a leitura de Ribeiro Telles sobre Lisboa coloca em evidência uma série de características rurais que inclui nos seus projectos, fazendo apelo à noção de genius loci.

Lisboa passou a ser objecto predilecto das suas preocupações, estudando a história e a evolução topográfica e ecológica da cidade, procurando intervir na salvaguarda da estrutura verde tradicional da periferia ainda predominantemente rural; deve-se-lhe o realce dado às quintas e hortas e à função crucial das velhas azinhagas que tanto serviam para a circulação pedonal como para drenagem das grandes quedas pluviométricas; aquele carácter rural de muitos aspectos de Lisboa inspirarou várias das suas intervenções, contribuindo assim, decisivamente, com os fundamentos para o desenvolvimento posterior da "escola" paisagista portuguesa, em que são evidentes quer a preocupação de manter a vegetação autóctone quer o tirar partido da situação ecológica e cultural dos sítios - o génio do lugar (id., ibid.: 29). 
Por respeitar a história da cidade mas também a vontade e a cultura das pessoas que nela vivem, Gonçalo Ribeiro Telles irá particularmente interessar-se pelas hortas urbanas.

Em Lisboa, existem 3000 hortas que são absolutamente indispensáveis a 3000 famílias para que não passem fome. (...) Não podemos tirar estas pessoas das hortas e metê-las em casarões, mesmo que tenham o Prémio Valmor. (...) Ficámos espantados quando, em 1987, se verificou que 3000 famílias em Lisboa passariam fome se não tivessem a sua horta de que pagavam renda à Câmara Municipal de Lisboa. Para além dos alimentos retiram apenas dois outros rendimentos: um, dos crisântemos, que vendem no dia de finados, e outro dos manjericos que vendem no mês dos santos populares. Pode acontecer que, num futuro, essas hortas - que hoje servem para ajudar a matar a fome - possam ser, como nas cidades europeias, para recreio. (...)

Temos que desenvolver condições para as populações que temos e não para aquelas que imaginamos ter (...) A cidade tem que traduzir a vontade e as necessidades das populações, respeitar a cultura, caso contrário estamos a fazer uma cidade no papel, contemplando apenas a estética, destinada a pessoas que não existem.

A cidade não pode degradar os centros históricos, nem as memórias que representam. Não podemos recuperar os centros históricos só para escritórios, nem exclusivamente para habitação de luxo ou mesmo apenas para o comércio, a população tradicional deve aí continuar a viver ou mesmo para eles voltar (id., ibid.: 18-19).

Ribeiro Telles defende a integração da ruralidade no interior da cidade sobretudo por razões históricas e culturais. "A cidade nasceu (...) da agricultura" (Pessoa 2002: 79). O espaço urbano permaneceu ao longo da sua história ligado ao espaço rural. A ruralidade faz parte da memória da cidade e da cultura das pessoas que nela vivem. A identidade ou, se quisermos, o genius loci de cidades como Lisboa assenta nas suas características rurais. Para Ribeiro Telles, a base da portugalidade encontra-se no mundo rural. E por isso a ruralidade deve continuar presente no espaço urbano. Esta preocupação em manter a identidade e a cultura de cada lugar e, em particular, do território português é herdada de Francisco Caldeira Cabral, fundador da arquitectura paisagista em Portugal.

\section{A ESCOLA DE FRANCISCO CALDEIRA CABRAL}

Francisco Caldeira Cabral estudou arquitectura paisagista na universidade de Friedrich-Wilhelm em Berlim entre 1936 e 1939. Em 1940 torna-se docente no Instituto Superior de Agronomia em Lisboa e inicia o ensino de arquitectura 
paisagista em Portugal com a organização de um curso experimental que, em 1942, passa a curso livre. Gonçalo Ribeiro Telles termina o curso livre em 1950. É o segundo arquitecto paisagista formado em Portugal. Em 1957 torna-se docente no Instituto Superior de Agronomia. Mantém uma relação próxima com Francisco Caldeira Cabral e colabora com ele em diversos projectos. Em 1958 trabalham em conjunto numa proposta para a estrutura verde da Lapa, em 1959 na estrutura verde do Plano de Urbanização de Lisboa, e em 1960 escrevem A Árvore em Portugal, que virá a marcar a teoria e a prática da arquitectura paisagista no nosso país.

Caldeira Cabral pensa pela primeira vez em estudar arquitectura paisagista fora do país quando, ainda estudante de agronomia, é, em 1935, convidado pela Câmara Municipal de Lisboa a apresentar uma proposta de trabalho para vir a ocupar o cargo de chefe da Repartição de Jardins e Cemitérios. Já aí, nessa proposta, manifesta o interesse pela adequação dos jardins às características específicas de Portugal.

Existiu entre nós uma escola de jardinagem que como é notório se perdeu de todo. Deu-se depois a costumada invasão das formas estranhas mal compreendidas por inadaptáveis ao nosso modo de ser psicológico e à nossa ecologia. (...) Necessita-se (...) de criar de novo o jardim moderno português, adaptado ao nosso país, às nossas condições económicas e até um pouco ao nosso gosto (cit. em Andresen 2003: 23).

Mais tarde, já arquitecto paisagista, Caldeira Cabral irá procurar estudar, definir, conservar e restabelecer as características do jardim português (ver Cabral 1993: 75-135), tal como Raul Lino o tinha feito em relação à casa portuguesa. Raul Lino era amigo de longa data da família de Caldeira Cabral e aconselhou-o a estudar arquitectura paisagista na Alemanha, onde ele próprio tinha estudado (ver Andresen 2003: 22 e 25). O percurso que Caldeira Cabral seguiu e, nesta medida, o da própria arquitectura paisagista em Portugal, não pode ser desligado da relação pessoal, profissional e intelectual que desde então manteve com Raul Lino. Na Alemanha, estabelece com ele uma relação epistolar e numa carta de 1936, na qual descreve o modo como o curso e a sua estadia em Berlim estão a decorrer, diz o seguinte: "Tenho ido muito ao Jardim Botânico que é muito interessante e onde vou estudando as plantas de jardim. Cultivam-se aqui imensas plantas que são espontâneas em Portugal e a que aí se não liga importância nenhuma" (cit. in id., ibid: 30).

Em Casas Portuguesas, já Raul Lino pedia que se passasse a utilizar a flora espontânea ou indígena do nosso país, até aí desprezada, na construção dos jardins (ver Lino 1992 [1933]: 81-83). E é precisamente isso que Caldeira Cabral irá fazer quando regressa a Portugal. Se os jardins eram até aí decorados e ornamentados com plantas estrangeiras, exóticas, muitíssimo valorizadas por 
serem raras, Caldeira Cabral irá defender e transmitir aos alunos que se devem plantar nos jardins as plantas espontâneas da região. Estas passam então a dominar os discursos e práticas dos arquitectos paisagistas formados pela escola criada por Francisco Caldeira Cabral, entre os quais se inclui Gonçalo Ribeiro Telles. Fernando Santos Pessoa comenta da seguinte forma os projectos de Ribeiro Telles:

[D]epois da inovação que constitui o Parque da Fundação Gulbenkian, em que praticamente só foram utilizadas espécies da nossa flora, realizou nos finais da década de 90 um jardim privado sobranceiro às falésias da Caparica, onde só a flora local foi empregue, sem sequer haver lugar para o tradicional relvado; o jardim é apenas o arranjo da vegetação da falésia, melhorada e redistribuída funcionalmente (op. cit.: 92).

E logo a seguir acrescenta: "Seria bom que os arquitectos paisagistas se diferenciassem dos outros construtores de jardins, e continuassem esta antiga luta da 'escola' que é a de utilizar a flora espontânea, tanto quanto possível, nas suas composições" (id., ibid.: 92). A Árvore em Portugal, escrito por Francisco Caldeira Cabral e Gonçalo Ribeiro Telles, consultado em diversos ateliês de arquitectura paisagista e também na Global, traduz este propósito da escola. Aí se recomenda o uso da vegetação espontânea, tradicional ou local, não apenas por razões ecológicas, mas sobretudo por questões culturais, porque são elas que mantêm o cunho local e o aspecto tradicional da paisagem (ver Cabral e Telles 1999: 53-54).

Caldeira Cabral não é, porém, o único a defender, no início dos anos 40, que a vegetação portuguesa devia substituir a estrangeira ou a exótica na ornamentação dos jardins. Em 1943, numa conferência proferida no âmbito da IV Exposição Nacional de Floricultura, João de Carvalho e Vasconcellos, professor no Instituto Superior de Agronomia, faz apelo ao uso da vegetação portuguesa nos jardins, parques e bermas de estradas.

Urge, pois, que os viveiros do Estado e das Câmaras Municipais criem e propaguem as plantas da nossa flora, (...), para que elas passem a aparecer com mais frequência nos nossos jardins e parques e não sejam substituídas por outras, muitas vezes de inferior aspecto e com certeza muito menos rústicas e adaptadas ao ambiente. Mas voltando de novo ao nosso tema, repetimos:

Um jardim com árvores e arbustos portugueses, as lindas flores do nosso país, o ouro da Giesta, a elegância dos Gamões, a beleza esquisita da Salapeira grande, a beldade consagrada na jardinagem mundial da Iris lusitanica é qualquer coisa nossa e querida, lume que acende a chama da Pátria, que lembra um regionalismo nobre e fará vibrar os corações da velha Nação portuguesa. 
Sim! O nosso País tem flores próprias, dignas de serem colocadas no altar de Nossa Senhora da Conceição, Padroeira de Portugal e êste facto não pode nem deve ser esquecido de todos os portugueses de nome, de alma e de sentimento! (Vasconcellos 1943: 15).

Aqui podemos ver, de um modo muito claro, como a defesa da flora portuguesa estava nesta altura associada a uma vontade de afirmação da identidade nacional. E é por este motivo que João de Carvalho e Vasconcellos sugere que se criem em Lisboa diversos jardins regionais com a extensa e diversificada flora existente na paisagem portuguesa.

Qualquer jardim desta natureza seria em Lisboa um pedaço de campo com toda a sua beleza, o seu aroma e a sua poesia. E mais, incentivo de amor ao nosso torrão, à nossa região, à nossa Pátria! Aí não haveria exotismos e todos os que por lá aparecessem deveriam ser inexoràvelmente expulsos. Tôdas as plantas cosmopolitas, ruderais e subespontâneas teriam que ser suprimidas para não conspurcarem o conjunto da flora regional.

Esses jardins assim constituídos não seriam só um atractivo para os nacionais, mas também para os turistas que nêles encontrariam qualquer coisa de diferente e belo que provavelmente muito apreciariam (id., ibid.: 6).

Das palavras de João de Carvalho e Vasconcellos podemos inferir que as plantas espontâneas, nativas ou indígenas são associadas ao campo. A afirmação da identidade e da cultura nacionais e o amor à pátria sustentam-se portanto no campo, onde se encontram as plantas propriamente portuguesas, e não na cidade, invadida por plantas estrangeiras. Também em 1933, Raul Lino defendia que a tradição e os valores portugueses se encontravam no campo e não na cidade, onde os velhos jardins desapareciam em prol da modernização (ver Lino 1992 [1933]: 84-85). As plantas do campo, as características rústicas das quintas e dos antigos jardins de província, e outras tipologias rurais passam então a ser valorizadas como especificamente portuguesas e como tal são conservadas ou inseridas no desenho e construção dos novos jardins. Nos jardins integrados no meio rural, como podemos ver no projecto de Caldeira Cabral, iniciado pelo próprio Raul Lino, para a renovação da Quinta da Agrela em Santo Tirso (cf. Andresen 2003: 160-163), mas também, e foi esta a proposta da escola fundada por Franscisco Caldeira Cabral hoje seguida por Gonçalo Ribeiro Telles e João Gomes da Silva, nos jardins da cidade.

Mas esta proposta nem sempre foi bem recebida. Trazer do campo as plantas espontâneas ou autóctones e outros elementos rurais nos quais supostamente assenta a identidade do sítio e introduzi-los nos jardins da cidade foi e continua a ser uma proposta por vezes violentamente contestada. Gonçalo Ribeiro Telles, quando esteve na Câmara Municipal de Lisboa e já depois de 
1958, elaborou o primeiro Plano Director Municipal, no âmbito do qual estudou um novo perfil para a Avenida da Liberdade. Em conjunto com Caldeira Cabral, decide escolher para este projecto a vegetação endógena e tradicional daquele lugar. Esta proposta foi rejeitada por alguns lisboetas, apoiados por alguns órgãos de comunicação social, por a considerarem inadequada a um contexto urbano, e o projecto nunca chegou a realizar-se. Como refere Fernando Santos Pessoa:

As propostas dos paisagistas de trazerem para os jardins urbanos o arvoredo da nossa flora, como o pinheiro manso, os carvalhos, os sobreiros, os medronheiros, as aroeiras (...) foi motivo de escândalo, e na imprensa exclamava-se com indignação: “A charneca entrou na cidade” (Pessoa 2002: 33).

Porém, quando se faz introduzir plantas e elementos rústicos em espaços urbanos e jardins privados, procede-se à sua recontextualização, reconfigurando-se assim os seus usos e significados. No campo, estas plantas e elementos detinham um uso agrícola e portanto estavam associados ao quotidiano do trabalho. Inseridos num jardim, público ou privado, não podem estar senão associados ao lazer. São agora utilizados como elementos ornamentais, sendo então apropriados e transformados por uma cultura urbana. Como dizia Rui Teles Palhinha em 1940 referindo-se às plantas espontâneas: "Mais tarde ainda chegarão a ver algumas das quais hão-de ser trazidas do campo para os jardins adquirir foros de citadinas" (Palhinha 1940: 11). Mas nem todos atribuem um significado lúdico e estético aos elementos rurais incluídos pela escola fundada por Francisco Caldeira Cabral nos jardins da cidade, pelo que os seus projectos são por vezes contestados.

A vegetação e as tipologias rurais consideradas representativas da identidade do sítio são, porém, esteticamente valorizadas por esta escola. Como esclarece Fernando Santos Pessoa:

$[\mathrm{O}]$ arquitecto paisagista deve criar beleza - é o que se aprende nos fundamentos da profissão.

A qualidade estética da obra paisagista resulta, em primeiro lugar, da utilização correcta dos materiais, vivos e inertes, mas também da interpretação das características do lugar onde actua - o que Ribeiro Telles chama de génio do lugar (Pessoa 2002: 86).

Também para João Gomes da Silva a qualidade estética de um projecto depende da sua articulação com o lugar. Recebe de Caldeira Cabral a definição augustiniana de beleza como "esplendor da ordem". A beleza é para Gomes da Silva ordem e harmonia, e a harmonia depende da adaptação do projecto às características ecológicas e culturais do lugar. Os projectos que se integram 
na paisagem envolvente ou que revelam o carácter ou a identidade do sítio onde se inscrevem são, portanto, esteticamente apreciados. Os critérios estéticos aqui presentes podem ser compreendidos através de um excerto de $A$ Árvore em Portugal.

Quando plantamos devemos também pensar qual a paisagem em que o vamos fazer. Hoje pretende-se que as plantações se integrem no ambiente que as rodeia. Não se devem por isso escolher espécies exóticas e de aspecto raro, por mais belas que nos pareçam. Devemos pedir às árvores o mesmo que deseja qualquer pessoa educada: não dar nas vistas! (Cabral e Telles 1999: 53-54).

O gosto pelas espécies exóticas e de aspecto raro é associado a uma estética do exagero e do extravagante, afectada e decorativista, decorrente dos prazeres imediatos, evidentes e corporais do divertimento, da fantasia e do agradável. A selecção de espécies endógenas ou autóctones, com a intenção de integrar um projecto na paisagem envolvente, sustenta-se, ao contrário, em noções de ordem, harmonia e equilíbrio que decorrem de uma estética dita mais cultivada, erudita, educada, intelectualizada e discreta. A introdução em jardins de plantas e tipologias rurais reveladoras da identidade do sítio assenta portanto nos critérios de gosto eruditos próprios de uma pessoa educada.

Plantas e tipologias rurais são inseridas em jardins como elementos simultaneamente dotados de significado histórico e estético. Adquirem assim uma dimensão lúdica. São agora elementos de excepção. Os únicos apropriados a um espaço de recreio, a um lugar extraordinário, como não pode deixar de ser um jardim. Gonçalo Ribeiro Telles convoca a história da relação entre o campo e a cidade para justificar a necessidade de integrar nos jardins urbanos características rurais. E ao fazê-lo participa da sua transformação. Através desse processo, atribui aos elementos rurais existentes no interior da cidade um valor histórico e, por consequência, estético que eles anteriormente não detinham. Confere-lhes uma mais-valia que os constitui como nobres, preciosos, inestimáveis. Torna-os dignos de um jardim. Esta mudança de contexto, de uso e de significado de plantas e tipologias rurais está associada a um processo de redescrição e reconfiguração do campo, assente na selecção de elementos preexistentes. Para fazer parte de cada projecto são apenas seleccionadas as preexistências que correspondem à imagem que os projectistas têm do mundo rural. Todos os elementos extrínsecos, exóticos, alheios à cultura do lugar - introduções recentes, estrangeiras, com um carácter moderno, industrial ou urbano - devem ser dele excluídos. Como dizia João de Carvalho e Vasconcellos por relação aos jardins regionais que seriam um pedaço de campo em Lisboa: "Aí não haveria exotismos e todos os que por lá aparecessem deveriam ser inexoràvelmente expulsos. Tôdas as plantas cosmopolitas, ruderais e 
subespontâneas teriam que ser suprimidas para não conspurcarem o conjunto da flora regional" (Vasconcellos 1943: 6). A identidade do lugar é construída através deste processo de selecção, inclusão e exclusão, de preexistências que, neste caso, assenta numa determinada imagem do mundo rural. Ao mesmo tempo que se define o lugar define-se também o que é o campo.

\section{O POPULAR ENTRE ARQUITECTOS E ARQUITECTOS PAISAGISTAS}

As imagens dos projectistas sobre o povo também intervêm neste processo de selecção. Pois, para a escola de Francisco Caldeira Cabral, é entre as classes populares, menos influenciadas por novos estilos e formas trazidas de fora, que podemos encontrar a cultura e a identidade que distingue cada lugar, região ou nação. Para encontrar as características do jardim português, Francisco Caldeira Cabral parece seguir, num primeiro momento, um critério de investigação social e geograficamente alargado. "Para esse fim todos nos devem interessar, desde os grandes jardins dos paços reais e de alguns conventos, até aos mais pequenos e modestos das nossas cidades - e mesmo os jardins rurais de algumas das nossas províncias, como o Minho" (Cabral 1993: 129). Contudo, é "nas pequenas obras feitas só pela nossa gente" que ele espera vir a encontrar, mais facilmente, as características próprias dos jardins portugueses.

É que justamente para encontrarmos as características nacionais dos nossos jardins, nem sempre os maiores e os mais ricos, em que a influência estrangeira porventura mais se faz sentir, são os mais indicados. As pequenas obras feitas só pela nossa gente podem mais facilmente, por esta razão e ainda pelo seu elevado número, indicar-nos características comuns (id., ibid.: 117).

O interesse manifestado por Gonçalo Ribeiro Telles pela vontade, modo de vida e cultura populares (e lembro que este é um dos seus argumentos para defender a manutenção da hortas em Lisboa) também assenta, pelo menos em parte, na defesa, enquanto monárquico, da identidade nacional. Fernando Santos Pessoa descreve-o como um

convicto partidário da Monarquia (...) de um regime de respeito pelas tradições históricas e culturais, e do envolvimento popular que, segundo ele, suportava o poder real nas velhas dinastias portuguesas antes da infiltração de valores estranhos à nossa identidade cultural. Nessa perspectiva, o Rei surgirá como garante da unidade nacional, apoiado no povo e não em forças partidárias ou económicas, situando-se acima destas (Pessoa 2002: 20).

Também João Gomes da Silva dedica particular atenção aos modos populares de construção da paisagem, por influência de Gonçalo Ribeiro Telles, mas 
também de Álvaro Siza Vieira, com quem colabora no seu primeiro projecto na Malagueira. É conhecido o interesse que o arquitecto Álvaro Siza Vieira revela nos seus primeiros projectos das décadas de 50 e 60 pela arquitectura popular, espontânea, vernácula ou regional. Esse interesse decorre aliás do contexto intelectual e arquitectónico do Porto, no qual se formou, marcado pelo espírito do Inquérito à Arquitectura Popular em Portugal realizado nos anos 50 (ver Leal 2000: 185-195). A aproximação de Álvaro Siza à arquitectura popular não é por isso independente da leitura que dela se construiu no Inquérito. Diversas equipas percorreram o país de automóvel, de scooter, a cavalo e a pé, recolhendo informação sobre "materiais e processos correntes de construção", "estrutura urbana", "influência do clima" e "influência das condições económicas" e "sociais" sobre a arquitectura e a formação dos aglomerados, "costumes, hábitos e outros factores condicionantes" da habitação, numa "aproximação contextualizada da arquitectura popular por referência às condições geográficas, económicas, sociais e 'etnológicas"” (ver id., ibid.: 170).

Para descrever e interpretar o popular, a arquitectura aproximou-se então da geografia e da etnologia. Orlando Ribeiro foi convidado a participar das reuniões preparatórias do trabalho de campo (cf. id., ibid.: 170). O próprio Orlando Ribeiro, para compreender a geografia do território português, dedicou particular atenção aos modos populares de construção da paisagem, estabelecendo por isso um diálogo privilegiado com a etnologia e, em particular, com José Leite de Vasconcellos e Jorge Dias (ver Ribeiro 1998 [1945]). Por seu turno, a etnologia também influenciou directamente o Inquérito, sobretudo a equipa que percorreu a zona de Trás-os-Montes e Alto Douro. "No capítulo sobre Trás--os-Montes, que de resto se inicia com uma referência a Jorge Dias, o diálogo com a etnografia é muito visível, predominando simultaneamente uma aproximação em 'close up' que valoriza o "estudo de caso"” (Leal 2000: 173).

Nas décadas de 60 e 70, alguns arquitectos do Porto permaneceram interessados na recolha de "expressões populares", aproximando-se dos etnólogos do grupo de Jorge Dias que viviam na mesma cidade (ver id., ibid.: 193). O diálogo criado durante este período entre etnólogos e arquitectos pode ser compreendido através da semelhança de perspectivas sobre a cultura popular. Quer os arquitectos do Porto fascinados pelo popular, quer os etnólogos do grupo de Jorge Dias, estavam sobretudo interessados na recolha e descrição da cultura material. Os objectos recolhidos e descritos só por si tornar-se-iam reveladores da cultura que os produziu. Como refere Jorge Freitas Branco por relação aos trabalhos de elaboração do Atlas Etnológico de Portugal do grupo de Jorge Dias: "os elementos recolhidos no terreno deverão ser explicados através da cultura e tendo em mente a preocupação comparativa. Objectifica-se a cultura" (Branco 1999: 34). Assim, se, por um lado, o grupo de Jorge Dias procurou definir metodologias e princípios científicos de recolha e descrição da cultura com a intenção de autonomizar e conferir autoridade ao discurso etnográfico 
(cf. id., ibid.: 33), por outro, ele perpetuou uma noção de etnografia que de algum modo se aproxima da metodologia utilizada pelos arquitectos da geração do Inquérito para estudar a cultura e, em particular, a arquitectura popular, mas também daquela que Francisco Caldeira Cabral sugere que se utilize na recolha e descrição das características dos jardins portugueses (ver Cabral 1993: 117 -1 18). João Vasconcelos fala-nos do duplo sentido da palavra etnografia.

Há uma acepção do termo, fortemente positivista, mas nem por isso totalmente abandonada, que o faz corresponder aos momentos de "recolha" e da "descrição" no processo de trabalho antropológico, sendo essas tarefas entendidas como compilação e exposição pormenorizadas de matéria bruta que carecerá depois de tratamento analítico. Contra esta noção impõe-se desde há muito a ideia de que qualquer descrição é necessariamente interpretativa e que reconhecê-lo e explicitar, na medida do possível, as condições em que a descrição é feita traz menos problemas epistemológicos do que pretender uma neutralidade impossível. Considera-se também que o trabalho do etnógrafo não é apenas inventariar factos, é sobretudo elaborar narrativas circunstanciais - geralmente por escrito, mas também através da exposição, da fotografia ou do cinema - que visem sistematizar e tornar inteligível a diferença sócio-cultural, reconstruindo, tanto quanto possível, nesse processo as vivências e as categorias internas ao retalho da existência humana estudado. (...) Tendo em mente o primeiro sentido, contudo, o termo é ainda hoje utilizado dentro da disciplina com uma carga pejorativa para referir sobretudo a actividade dos colectores de objectos e costumes serôdios (Vasconcelos 2001: 428).

Quer o grupo de Jorge Dias, quer os arquitectos e os arquitectos paisagistas que referimos, recorrem ao primeiro sentido da palavra etnografia ao tomarem as construções populares como um facto cultural a registar, a inventariar e a descrever. É este primeiro sentido da palavra etnografia, do qual a maioria dos antropólogos de hoje se afasta, que aproxima ainda hoje arquitectos e arquitectos paisagistas como João Gomes da Silva e o seu colaborador Sebastião Carmo Pereira das etnografias realizadas pelo grupo de Jorge Dias.

Sebastião Carmo Pereira foi um dos meus principais interlocutores durante o período em que estive no ateliê de João Gomes da Silva. Falou-me do seu interesse pela paisagem popular e contou-me que trabalhava nesse momento num projecto de concepção de um museu sobre a antiga Aldeia da Luz com Benjamim Pereira, Clara Saraiva, Catarina Mourão e Catarina Alves Costa, no âmbito do qual lhe cabia a tarefa de efectuar, conjuntamente com um fotógrafo, o levantamento da paisagem popular e rural da região. Sebastião lera os textos publicados pelo grupo de Jorge Dias sobre tecnologias e construções populares. Falava com grande apreço e admiração do trabalho desenvolvido por 
este grupo, ao qual Benjamim Pereira, com quem agora colaborava, também pertenceu. E a Arquitectura Tradicional Portuguesa de Ernesto Veiga de Oliveira e Fernando Galhano, embora desprovida do olhar global sobre a paisagem que caracteriza a arquitectura paisagista, era para ele uma obra de referência no estudo da arquitectura popular em Portugal.

Esta valorização dos "sistemáticos empreendimentos etnológicos de recolha patrimonial "de urgência” em que Jorge Dias e, sobretudo, Ernesto Veiga de Oliveira, Benjamim Pereira e Fernando Galhano se empenharam durante longos anos" (id., ibid.: 427), de algum modo, pressupõe uma aceitação das imagens do povo que através daqueles etnólogos se construíram. Jorge Freitas Branco apresenta-nos uma análise crítica destas imagens.

As principais questões que delas sobressaem são a visão sociologicamente indiferenciada do povo, a consequente defesa duma operacionalização da pesquisa em torno da noção de autêntico, o programa desta forma implícito de estabelecimento de um corpus específico da cultura popular, a rejeição da cultura de massas. Quer isto dizer que os comportamentos considerados adulterados ou contaminados (influência urbana, emigração, meios de comunicação social, diferenciação geracional), em vez de vistos como componentes de uma dinâmica social, eram simplesmente reprovados, promovendo-se outros, como que num acto de purificação. Uma tal atitude revela a pretensão de um grupo na sociedade de construir um olhar hegemónico sobre o seu todo (Branco 1999: 37).

O povo é definido por estes etnólogos como um grupo social uniforme e específico com base na noção de autenticidade. Como refere João de Pina Cabral:

Deverá ser entre "o povo", e não entre as classes urbanas no poder, que se poderá encontrar a “autenticidade nacional”. (...) Em 1983 Viegas Guerreiro coloca a questão da seguinte forma: "É no povo, em sua espontaneidade, em sua autenticidade, mais do que em qualquer outra classe, que podemos encontrar os elementos da cultura por que esta melhor se define e não na sofisticada sociedade das letras". Assim, embora o conceito de "povo português" inclua, em princípio, todos os cidadãos portugueses, o facto é que, em vários contextos, a polissemia do conceito permite a exclusão das classes sociais no poder (Pina Cabral 1991: 16-17).

Mas quem confere autenticidade ao povo são precisamente as classes urbanas no poder que dele se excluem. É por isso a burguesia quem define, selecciona e purifica, através dos seus próprios critérios de autenticidade, aquilo que faz parte da cultura popular. Daí resulta, como demonstra mais uma vez João de Pina Cabral, uma atitude ambivalente para com o povo. 
[A] procura levada a cabo pela burguesia "culta" de uma identidade nacional e da sua ancestralidade na cultura popular é contraditória, pois ela é acompanhada por uma atitude paternalista de desrespeito e superioridade. Embora a essência "autêntica" da nacionalidade deva ser encontrada no "povo", o "verdadeiro" conhecimento da nacionalidade (a capacidade de a distinguir, de a definir com autoridade) é um privilégio burguês (id., ibid.: 19).

Assim, ao mesmo tempo que a burguesia se envolve na descrição e purificação de uma cultura popular portuguesa e autêntica, coloca-se em relação a ela numa posição distanciada de autoridade e superioridade.

A noção de autenticidade utilizada pela elite intelectual burguesa na construção da cultura popular produz por relação a ela um afastamento temporal. "A autenticidade é definida tanto por referência ao que é único para um povo como ao que tem uma já longa existência: é portanto inseparável da noção de 'primitivo', da temporalização da diferença" (id., ibid.: 17). Com base na noção de autenticidade elabora-se portanto uma oposição entre cultura popular, ancestral e autêntica, e a elite intelectual burguesa, moderna e descaracterizada. "[É] construída uma genealogia fictícia na qual os costumes populares são 'autênticos' porque são ancestrais, em oposição aos costumes da burguesia urbana que, embora inequivocamente hegemónicos, não são 'típicos', porque são "modernos'" (id., ibid.: 18). A autenticidade e a ancestralidade atribuída à cultura popular resulta portanto num e de um processo de selecção e purificação. “[O] popular de hoje é rejeitado como 'má cultura'; o popular de ontem é co-optado como "tradicional'” (id., ibid.:19). Os sistemáticos empreendimentos etnológicos de recolha patrimonial "de urgência” do grupo de Jorge Dias participam neste processo de construção do popular. Daí a rejeição da cultura de massas e a reprovação de todos os comportamentos considerados adulterados pela influência urbana, emigração ou meios de comunicação social. A Jorge Dias "resta-lhe proceder ao relato duma cultura popular em vias de apagamento, como tributo devido ao progresso" (Branco 1999: 36).

Os arquitectos associados directa ou indirectamente ao Inquérito estabeleceram um diálogo com os etnólogos do grupo de Jorge Dias em torno da cultura popular. Os ecos desse diálogo ainda hoje se fazem sentir em diversos arquitectos e arquitectos paisagistas, nomeadamente em João Gomes da Silva e em Sebastião Carmo Pereira que, como vimos, ainda hoje refere e aprecia os textos desses etnólogos. A leitura que estes dois arquitectos paisagistas fazem da paisagem vernacular não questiona a imagem da cultura popular construída por aqueles etnólogos através da noção burguesa de autenticidade associada ao tradicional, dando-lhe, justamente, continuidade. Para Gomes da Silva, as referências, os valores, os modos de construção populares mantêm-se ao longo do tempo. Podemos por isso neles encontrar a cultura e a identidade específica e distintiva de um dado lugar. Se Ernesto Veiga de Oliveira considera que "um 
tipo de habitação resulta, as mais das vezes, de uma longa evolução; ele resume a experiência de gerações de gentes da terra" (Oliveira e Galhano 2000: 14), também Gomes da Silva afirma numa entrevista que a paisagem se organiza de determinada maneira porque isso corresponde a uma forma de cultura consolidada ao longo de séculos. Os modos populares de construção e organização da paisagem descritos por Gomes da Silva através de imagens do popular que reforçam a sua ancestralidade e autenticidade tornam-se para ele reveladores da cultura que marca a identidade específica de um lugar, sendo, deste modo, esteticamente valorizados.

Esta valorização estética ou esteticização da paisagem popular não resulta porém de uma aproximação de Gomes da Silva ao gosto popular. ${ }^{1} \mathrm{Na}$ verdade, ela assenta na noção burguesa de autenticidade e nos princípios de harmonia, equilíbrio e discrição próprios de uma "pessoa educada”, a usar as palavras de Francisco Caldeira Cabral. Através dos seus próprios critérios de gosto, valorizando a integração subtil e harmoniosa na paisagem envolvente, Gomes da Silva observa, selecciona, purifica e constrói o popular. Nesta concepção de arquitectura paisagista, as construções consideradas adulteradas ou contaminadas pela influência urbana, emigração, meios de comunicação social ou cultura de massas são rejeitadas, porque incompatíveis com a cultura ancestral e autêntica do lugar, quebrando, assim, a harmonia, a simplicidade e o equilíbrio que, nos seus termos, conferem beleza à paisagem. A seguir sempre de perto esta concepção de arquitectura paisagista, Gomes da Silva rejeita então todos os exotismos e decorativismos perturbadores da ancestral e autêntica cultura popular, construindo uma imagem idealizada do povo como um grupo social cujo gosto se mantém ao longo do tempo.

A Gomes da Silva interessa-lhe compreender e reconfigurar pela sua prática projectual o popular de ontem e não o de hoje, entendido como "má cultura", a parafrasear o já citado João de Pina Cabral (op. cit.: 19). Pois é esse tal popular de ontem que marca a identidade própria e distintiva de cada lugar. E é esta identidade distintiva que Gomes da Silva procura resgatar e manter. Interessa-lhe assim descrever e interpretar a cultura objectificada na paisagem e não a das pessoas que nela vivem. E por isso recorre à análise tipológica. ${ }^{2}$ Todos os

1 João Gomes da Silva, tal como Siza Vieira, recusa a ideia do arquitecto como a "mão do povo". É ao arquitecto que cabe a tarefa e a responsabilidade de saber construir. A arquitectura é para ele a grande construção, a construção culta, erudita ou elevada. E, segundo ele, o saber ou a cultura erudita distingue-se do popular por ser mais global e universal detendo sobre este autoridade.

2 Gomes da Silva procura inferir, através da análise tipológica da paisagem, a cultura das pessoas que a construíram e organizaram ao longo do tempo. Os espaços não são pensados de acordo com o sentido que as pessoas lhes atribuem, mas ao contrário, são as pessoas que são definidas, representadas e classificadas de acordo com os espaços onde residem. São estes que indicam qual a cultura própria do lugar e, logo, aquela que deve ser incorporada pelas pessoas que nele vivem. São os espaços que ditam quem e como deve aí residir. 
seus projectos partem portanto da sua leitura/compreensão da paisagem preexistente. E é nas características rurais e nas construções populares de cada lugar que ele espera vir a encontrar a sua identidade. Gomes da Silva selecciona, descontextualiza e transforma então com cada um dos seus projectos as preexistências que correspondem à sua imagem do rural e do popular. Veremos agora como isso acontece na Unidade de Ecoturismo da Herdade de Freixo.

\section{DESTACAR E DAR A VER PREEXISTÊNCIAS RURAIS E POPULARES NUM NOVO CONTEXTO}

Em 2003 tive a oportunidade de acompanhar o processo de concepção de um projecto para uma propriedade agro-pecuária em Montemor-o-Novo. O programa consistia em construir nesta propriedade uma unidade de ecoturismo. O objectivo era por isso associar à produção agro-pecuária os intentos turísticos de lazer, contemplação e fruição estética. Ou, se quisermos, o objectivo era revelar o valor estético da paisagem rural preexistente. A ideia era então desenhar um caminho que percorresse e destacasse os lugares mais notáveis.

Gomes da Silva e Sebastião Carmo Pereira observam a carta da Herdade de Freixo exposta na parede do seu ateliê. Procuram os lugares a destacar. Referem alguns. Sentem que será necessário consultar uma fotografia aérea. Esboçam uma primeira ideia sobre o caminho a traçar. Vão até ao ateliê do arquitecto Carrilho da Graça situado na mesma rua. É com ele e com o arquitecto Francisco Freire que elaboram este projecto. Também aqui se expõe na parede um mapa da herdade onde irão intervir. Sobre ele está um papel vegetal com uma recta marcada a vermelho. Esta recta liga o Monte da Pedra Alta ao Moinho dos Castelos Velhos. Estes são dois dos lugares a realçar. Serão eles as extremidades do percurso a construir. Gomes da Silva concorda com esta proposta que coincide com a sua leitura do sítio. Entusiasmado, relata que lera um artigo que poderia servir como referência para este projecto.

Este artigo é de Georges Descombes (1999). É sobre a sua participação no projecto de construção de um caminho à volta do lago Uri, concebido para comemorar os setecentos anos da confederação suiça em 1991. Cada um dos vinte seis cantões da Suíça surge representado numa secção do caminho, de acordo com a sua ordem de entrada na confederação e com a proporção da sua população no total da Suíça. Georges Descombes trabalha com os artistas Richard Long, Carmen Perrin e Max Neuhaus na secção correspondente ao cantão de Génova.

Eu comecei a pensar sobre o projecto percorrendo o sítio várias vezes. Despendi muito tempo ao olhar simplesmente para as coisas. Tentei observar aquilo que normalmente não vemos, tal como flores e ratos, e tudo o que se move à volta dissimuladamente, com o desejo de permanecer imperturbado. 
Ao mesmo tempo, pretendia deixar uma marca do nosso tempo, impor um traço inequívoco da nossa actividade. Em outras palavras, queria respeitar a natureza do sítio e a sua história, mas sem nostalgia, sem sentimentalismo.

Então, nós decidimos não colocar nada no caminho que já lá não estivesse. Queríamos enfatizar as suas qualidades inerentes ao mesmo tempo que revelávamos as escondidas. Um pressuposto típico da arquitectura é que se acrescenta sempre algo a um lugar. Escolhemos fazer exactamente o oposto; fomos retirando coisas. Retirámos tudo aquilo que estava errado - enquadramentos pitorescos, más construções kitsch, e áreas excessivamente ocupadas. Tudo o que precisávamos já ali estava, e o nosso trabalho era simplesmente encontrar e re-presentar estas características através de uma arquitectura discreta. Assim, procurámos clarificar a paisagem, amplificar as suas características através da subtracção e de uma intervenção modesta - embora muito calculada.

(...) Não quisemos cobrir o lugar com procedimentos analíticos e de investigação mas perturbar parcialmente a sua organização de modo a simultaneamente revelar e apreciar a sua essência. Também quisemos utilizar esta estratégia para renovar as emoções das pessoas que percorressem o lugar - chamar a sua atenção para a magia do quotidiano (Descombes 1999: 82-83 - tradução minha).

Encontrar e re-presentar as características ou elementos já presentes no sítio através de uma arquitectura discreta não tem nada de simples, ao contrário do que afirma Descombes. Que características e elementos são estes? Que características e elementos seleccionar? Esta selecção é feita através do olhar do projectista e, mais uma vez, o olhar não tem nada de simples. Não são as coisas que se revelam através do olhar, mas a forma como elas são recebidas, percepcionadas, estruturadas pelo observador. O olhar organiza, interpreta, transforma aquilo que se vê de acordo com a linguagem e cultura visual do espectador. Neste sentido, encontrar, revelar ou destacar as características ou elementos já presentes na paisagem é nela intervir. É transformá-la de acordo com as noções estéticas, políticas e sociais do projectista. E retirar o que se considera estar a mais, ou seguir a lógica da subtracção é, da mesma forma que acrescentar ou adicionar, agir sobre o sítio. É transformá-lo através da leitura que sobre ele se construiu. Georges Descombes, de alguma forma, sabe que o seu projecto para o Swiss Way, em Génova, acaba por transformar o sítio no qual se insere, ou pelo menos a percepção que dele se tem. E é isso que pretende.

Para mim, recuperar alguma coisa - um sítio, um lugar, uma história ou uma ideia - implica uma mudança de expectativa e ponto de vista.

O meu trabalho é essencialmente tentar alcançar tais mudanças de complexidade com o mínimo de meios. (...) Eu procuro a precisão da disposição, 
articulação, organização - arquitectura - de modo a que um lugar preexistente possa ser encontrado, perturbado, despertado, e se torne presente. Eu tento alcançar uma arquitectura do lugar, uma construção que sacuda o seu contexto, arranhe a banalização de uma situação, e imponha uma mudança naquilo que parece ser óbvio. Espero que o meu trabalho funcione como um meio que vai revelando forças que são (ou se tornaram) imperceptíveis, gerando um sentimento de singularidade, criando a fonte de uma atenção diferente, uma visão diferente, uma emoção diferente. Para mim, a principal dificuldade da intervenção na paisagem é como tornar certas forças activas e, daqui, como fazer novas formas, criar novos sentimentos e associações (id., ibid.: 79 - tradução minha).

Gomes da Silva recorre a este artigo para explicitar o que pretende fazer no seu projecto para a Herdade de Freixo. Ele também pretende revelar ou destacar os elementos ou lugares mais significativos. Através de intervenções discretas e minimais, propõe-se criar um novo ponto de vista sobre estes lugares, novos sentimentos e associações. Pretende descobrir um caminho que os articule e dê a ver. Pretende construir uma metapaisagem ou uma nova leitura e um outro olhar sobre a paisagem preexistente. Pretende mostrar a sua singularidade, a sua magia, a sua beleza. Revelar o valor estético e artístico dos lugares que fazem parte do quotidiano. Este projecto cria então uma rede de percursos pedonais entre os lugares a recuperar ou a realçar como valores individualizados. Aos arquitectos cabe a tarefa de recuperar os montes com mais "interesse", que se encontram dispersos, de acordo com uma lógica particular, ao longo do rio e dos pontos mais altos. Os arquitectos paisagistas seleccionam e revelam outras tipologias. As hortas, que se encontram perto dos montes ou casas a recuperar, serão convertidas em hortos, em espaços reservados e delimitados associados ao recreio e prazer. Segundo Gomes da Silva, as hortas são sempre lugares de excepção numa paisagem de floresta como é o montado existente nesta propriedade. Algumas estão encaixadas nas formas dos próprios barrancos. Uma outra é seleccionada por ser muito bonita, porque é um círculo perfeito e tem uma forma muito original. Destacam-se também maciços rochosos. Destaca-se em especial a Pedra Alta. Uma rocha, segundo Gomes da Silva, com muito valor, muito conhecida e bonita, identificada na toponímia. Destacam-se as fontes. Chama-se também a atenção para as manchas de pinhal que aparecem em destaque relativamente ao montado. As ruínas existentes servirão de suporte à construção de eremitérios ou abrigos. Lugares que se configuram como lugares especiais por serem altos, ou por terem uma boa visibilidade ou porque se relacionam visualmente com outros. São lugares de paragem e contemplação. Pressupõem um certo isolamento e ajudam a controlar e a conferir uma certa intensidade ao uso do território. Gomes da Silva diz que seguiu aqui a lógica da ocupação territorial das cercas dos monges Capuchos. As cercas 
delimitam uma propriedade, criando refúgios ou eremitérios como aqueles que existem em Sintra ou na Arrábida. Normalmente correspondem a situações naturalizadas e contemplativas. Ao longo do rio destacam-se ilhas, pegos e passagens que articulam a propriedade com o seu exterior. Estas passagens inserem-se, segundo Gomes da Silva, numa rede de caminhos que ligam os diversos montes entre si. Procura aqui seguir a lógica desta rede de caminhos, que segundo ele é a do povoamento e construção da paisagem alentejana, e cria percursos pedonais que ligam e destacam os diversos lugares ou elementos de excepção que acabámos de referir. Cria um percurso ao longo do rio que estrutura a experiência de um espaço "muito encaixado". E cria um outro ao longo das cumeadas que permite ver do alto a paisagem.

É nas tipologias rurais e nas construções populares que Gomes da Silva espera vir a encontrar, como já referimos, o passado, as memórias e as referências que marcam um território. Neste projecto, são por isso seleccionados como lugares arqueológicos ${ }^{3}$ ou elementos reveladores da cultura do lugar hortas e fontes, maciços rochosos, pegos e passagens a vau do rio Almansor. Estes elementos ou lugares são assim descontextualizados, objectificados, ressemantizados (Handler 1988). São retirados do seu contexto, perdendo o uso e o significado que aí detinham. São agora apresentados isoladamente como traços típicos e distintivos deste lugar. Surgem agora no contexto deste projecto e nele adquirem um novo uso e significado, assumindo um significado estético. São agora configurados como lugares ou elementos notáveis, excepcionais, especiais. Adquirem uma dimensão lúdica, adaptada ao novo uso turístico que se pretende conferir a este território. As hortas são então convertidas em hortos. Anteriormente associadas a uma função produtiva e ao quotidiano do trabalho, são agora espaços de lazer e recreio. Também as fontes, os maciços rochosos, os pegos e passagens, anteriormente associados a práticas sociais e espaciais quotidianas, adquirem, enquanto elementos reveladores da identidade do sítio, um significado estético, lúdico e de excepção.

Gomes da Silva realça que as passagens a vau do rio Almançor se inserem numa rede de caminhos que seguem a lógica do povoamento e construção da paisagem alentejana. Refere que no Alentejo os caminhos interligam os diferentes montes entre si, dando origem a figuras, normalmente em estrela, centradas nos montes. Esta rede de caminhos torna-se, para Gomes da Silva, representativa da paisagem alentejana e, como tal, procura reproduzi-la neste projecto. Mais uma vez estes traços resultantes de práticas sociais são descontextualizados, obectificados e ressemantizados. Deixam de ser caminhos que as pessoas percorrem no seu dia-a-dia no contexto das suas vidas e das suas

3 Lugares arqueológicos não são, nas palavras de Gomes da Silva, os lugares estudados e valorizados pela arqueologia enquanto disciplina. Na definição de João Gomes da Silva, os lugares arqueológicos são aqueles que permitem restaurar a memória, o passado e as referências que marcam um território. 
diversas actividades sociais e passam a ser apresentados como traços típicos e distintivos da paisagem alentejana. $\mathrm{Na}$ verdade, como se refere na memória descritiva deste projecto de ordenamento paisagístico para o ecoturismo na Herdade de Freixo, "a criação por aproveitamento ou reconstrução de uma rede de percursos pedonais" tem como novo propósito permitir "uma experiência rica e clara da identidade da Paisagem da Herdade de Freixo". Esta rede de caminhos preexistente é agora aproveitada e recuperada, apropriada e transformada, com a intenção de dar a ver os elementos e lugares considerados histórica e esteticamente significativos. Estes percursos são agora pensados, como se refere na mesma memória descritiva, "enquanto forma de experiência e contemplação, mas sobretudo enquanto exercício de re-creação [sic] e restabelecimento físico e psicológico".

Portanto, neste seu projecto para a Herdade de Freixo, João Gomes da Silva, em colaboração com o arquitecto paisagista Sebastião Carmo Pereira e os arquitectos Francisco Freire e João Luís Carrilho da Graça, selecciona, destaca e dá a ver uma série de preexistências que considera fazerem parte da vida, da cultura e da memória das pessoas que a habitam, permitindo, assim, revelar a identidade deste lugar. Por exemplo, ele afirma que inclui a Pedra Alta neste projecto porque ela se impóe como uma referência para todos aqueles que conhecem e vivem nesta propriedade. Esta pedra está na toponímia. O proprietário da herdade foi das primeiras coisas que lhe mostrou. E também os "camponeses" 4 falam dela. Contudo, ao retirar estas preexistências do seu contexto social e ao apresentá-las isoladamente neste projecto de arquitectura paisagista como traços típicos e distintivos deste lugar, ele está a alterar o seu sentido. Elas perdem o sentido que tinham para as pessoas que as utilizavam, construíram ou delas falavam e adquirem o significado que o projecto lhes imprime. São seleccionadas, apropriadas e transformadas através da linguagem e das concepções sociais, estéticas e disciplinares de João Gomes da Silva que, como vimos, é herdeiro de Gonçalo Ribeiro Telles e, através dele, de Francisco Caldeira Cabral. Para a escola fundada por Francisco Caldeira Cabral a identidade de cada lugar assenta nas suas características rurais e populares. Através dos critérios estéticos de ordem, harmonia e discrição próprios de uma pessoa dita educada, estas características são então esteticamente apreciadas. Assim, embora Gomes da Silva tenha seleccionado e incluído neste projecto as preexistências que, segundo ele, faziam parte da cultura, da vida e da memória das pessoas que aí viviam, nelas inserindo os "camponeses", tais preexistências são por ele interpretadas e transformadas através dos critérios de gosto eruditos, da noção burguesa de autenticidade e das imagens do povo e da ruralidade que recebeu da tradição disciplinar na qual se integra. Na verdade, João Gomes da Silva não procurou falar com as pessoas que viviam na Herdade de Freixo e, 
em particular, com os "camponeses", na tentativa de compreender qual o uso e o significado que atribuíam às preexistências seleccionadas. Não procurou conhecer ou investigar quais os lugares e elementos que hoje se destacam no contexto das suas vidas. E quando eu própria me propus fazê-lo, reagiu de uma forma evasiva e irónica. João Gomes da Silva não pretendia com este projecto para a Herdade de Freixo ir ao encontro do modo de vida, do gosto e do universo de sentido dos "camponeses" ou das outras pessoas que aí viviam. Pretendia apenas recuperar e dar a ver como lugares ou elementos notáveis e especiais, dotados de valor histórico-cultural, estético e artístico, uma série de preexistências para ele reveladoras da identidade do sítio, de modo a permitir a fruição turística deste território. E com esse objectivo, recorreu aos seus próprios critérios de gosto, noções e referências. Recorreu à noção de percurso enquanto experiência e contemplação. Recorreu a tipologias e a construções paisagísticas que esteticamente valoriza, como os hortos e as cercas dos monges Capuchos. Recorreu à sua imagem do povo, da ruralidade e do Alentejo e seleccionou, como traços representativos da identidade do sítio, hortas, fontes, maciços rochosos, pegos e passagens inseridas em caminhos que interligam em estrela os diversos montes entre si.

\section{BIBLIOGRAFIA}

ANDRESEN, Teresa (coord.), 2003, Do Estádio Nacional ao Jardim Gulbenkian. Francisco Caldeira Cabral e a Primeira Geração de Arquitectos Paisagistas (1940-1970). Lisboa, Fundação Calouste Gulbenkian.

BARRJERE, Armelle, 1998, Réaménagement des Espaces Vertes de Malagueira, Évora, Portugal. Relatório de estágio para a École Nationale Supérieure du Paysage de Versailles, não publicado.

BRANCO, Jorge Freitas, 1999, "A fluidez dos limites: discurso etnográfico e movimento folclórico em Portugal”, Etnográfica. 3 (1): 23-47.

CABRAL, Francisco Caldeira, 1993, Fundamentos da Arquitectura Paisagista. Lisboa, Instituto da Conservação da Natureza.

CABRAL, Francisco Caldeira, e Gonçalo Ribeiro Telles, 1999, A Árvore em Portugal. Lisboa, Assírio \& Alvim.

DESCOMBES, George, 1999, "Shifting sites: the swiss way, Geneva", em James Corner (ed.), Recovering Landscape. Essays in Contemporary Landscape Architecture. Nova Iorque, Princeton Architectural Press, 79-100.

HANDLER, Richard, 1988, Nationalism and the Politics of Culture in Quebec. Wisconsin, University of Wisconsin Press.

LINO, Raul, 1992 [1933], Casas Portuguesas: Alguns Apontamentos sobre o Arquitectar de Casas Simples. Lisboa, Edições Cotovia. 
LATOUR, Bruno, e Steve Woolgar, 1986 [1979], Laboratory Life: The Construction of Scientific Facts. Princeton, Princeton University Press.

LEAL, João, 2000, Etnografias Portuguesas (1870-1970): Cultura Popular e Identidade Nacional. Lisboa, Publicações Dom Quixote.

NORbERG-SCHUlZ, Cristian, 1981 [1979], Genius Loci. Paysage, Ambiance, Architecture. Bruxelas, Pierre Mardaga Éditeur.

OLIVEIRA, Ernesto Veiga de, e Fernando Galhano, 2000, Arquitectura Tradicional Portuguesa. Lisboa, Publicações Dom Quixote.

PAlHinha, Rui Teles, 1940, Flôres Portuguesas, Porque as Não Empregar?. Lisboa, Publicações Culturais da Câmara Municipal de Lisboa.

PESSOA, Fernando Santos, 2002, Gonçalo Ribeiro Telles. Esboço Biográfico. Lisboa, Costa do Castelo Filmes.

PINA CABRAL, João de, 1991, Os Contextos da Antropologia. Lisboa, Difel.

RIBEIRO, Orlando, 1998 [1945], Portugal, o Mediterrâneo e o Atlântico. Lisboa, Livraria Sá da Costa Editora.

SIlva, João Gomes da, 1987, Plano de Pormenor da Malagueira. Projecto de Espaços Exteriores - Programa Base. Plano de Estrutura Verde. Évora, Câmara Municipal de Évora.

TElles, Gonçalo Ribeiro, 1996, Um Novo Conceito de Cidade: a Paisagem Global. Matosinhos, Contemporânia Editora Ld. ${ }^{\mathrm{a}}$, Câmara Municipal de Matosinhos.

VASCONCELlOS, João de Carvalho e, 1943, O Jardim Regional. Lisboa, Publicações Culturais da Câmara Municipal de Lisboa.

VASCONCELOS, João, 2001, “Estéticas e políticas do folclore”, Análise Social. 36 (158-159): 399-433.

\section{The uses of rurality in landscape architecture}

\section{Sandra Xavier}

Departamento de Antropologia da Faculdade de Ciências e Tecnologia da Universidade de Coimbra.

sandrax@ci.uc.pt

In this article, I will focus on the landscape architecture projects of João Gomes da Silva using Richard Handler's concept of cultural objectification. João Gomes da Silva is a follower of the landscape architecture school of Francisco Caldeira Cabral and uses rural typologies as elements representing the identity of the place in public and private gardens, and in public and urban spaces. He is also influenced by the architect Álvaro Siza Vieira and by the Inquérito à Arquitectura Popular em Portugal, paying particular attention to the folk modes of constructing the landscape. In his projects, these folk modes are shown as representative elements of the culture of the place and they are aesthetically valued as such.

KEYWORDS: Landscape architecture, genius loci, rural typologies, folk constructions, objectification, aesthetic. 